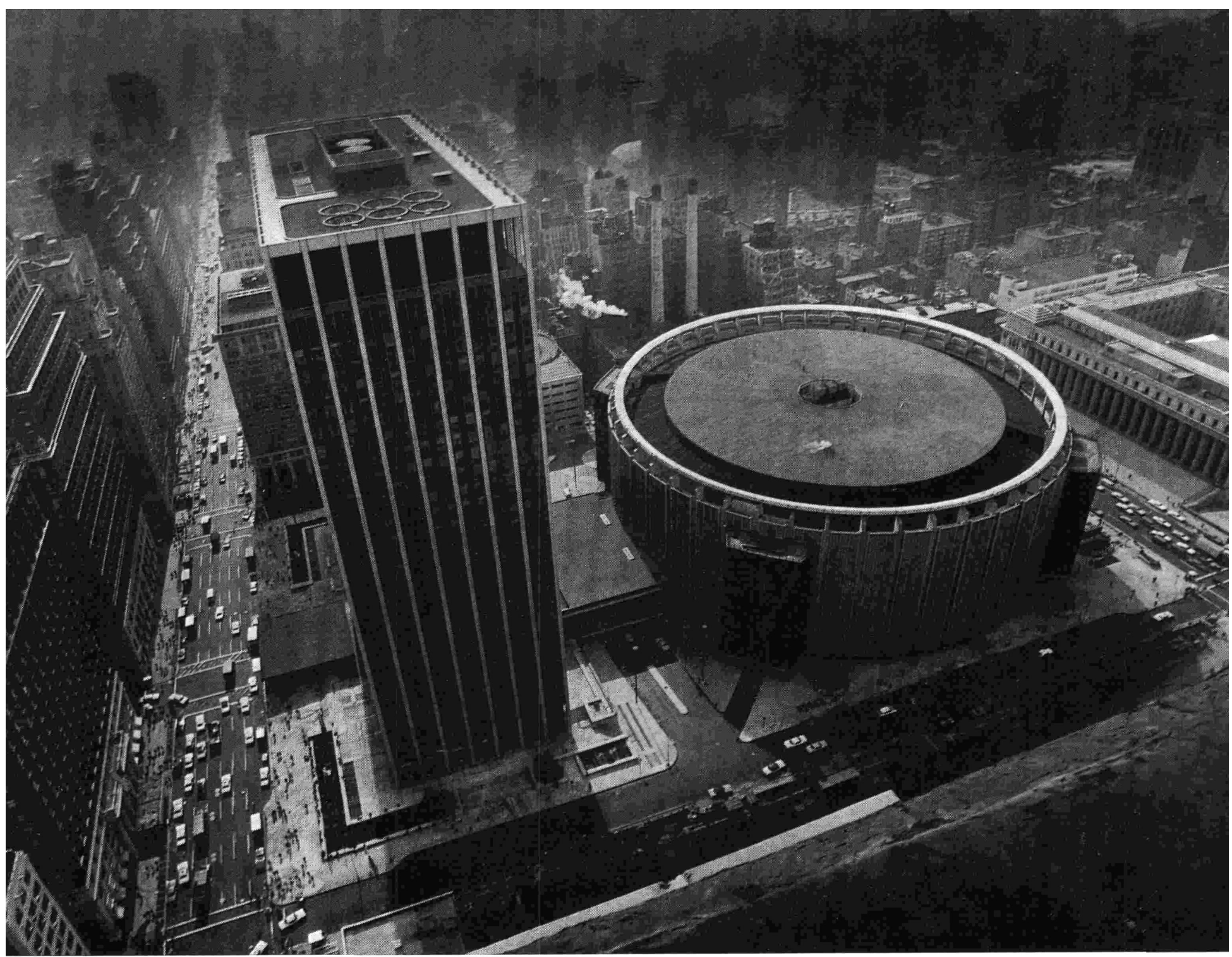

\title{
el nuevo madison square garden
}

EE.UU

CHARLES LUCKMAN, arquitectos asociados

\section{sinopsis}

Forman parte del Centro Deportivo y de Atracciones Madison Square Garden:

1) Un edificio circular, de $129,54 \mathrm{~m}$ de diámetro y $45,72 \mathrm{~m}$ de altura, que aloja el Nuevo Madison Square Garden y otras muchas instalaciones. Tiene capacidad para 20.250 asientos, y en él se pueden celebrar espectáculos de: hockey, baloncesto, ciclismo, boxeo, circo, patinaje sobre hielo, acontecimientos especiales, variedades, asambleas y otros deportes de masas, etc.

2) Un edificio de oficinas que se alza contiguo a la Séptima Avenida, con una superficie útil de $111.500 \mathrm{~m}^{2}$ destinada a oficinas, y otra de $4.800 \mathrm{~m}^{2}$, en las plantas primera y segunda, dedicada a actividades comerciales y bancarias. 


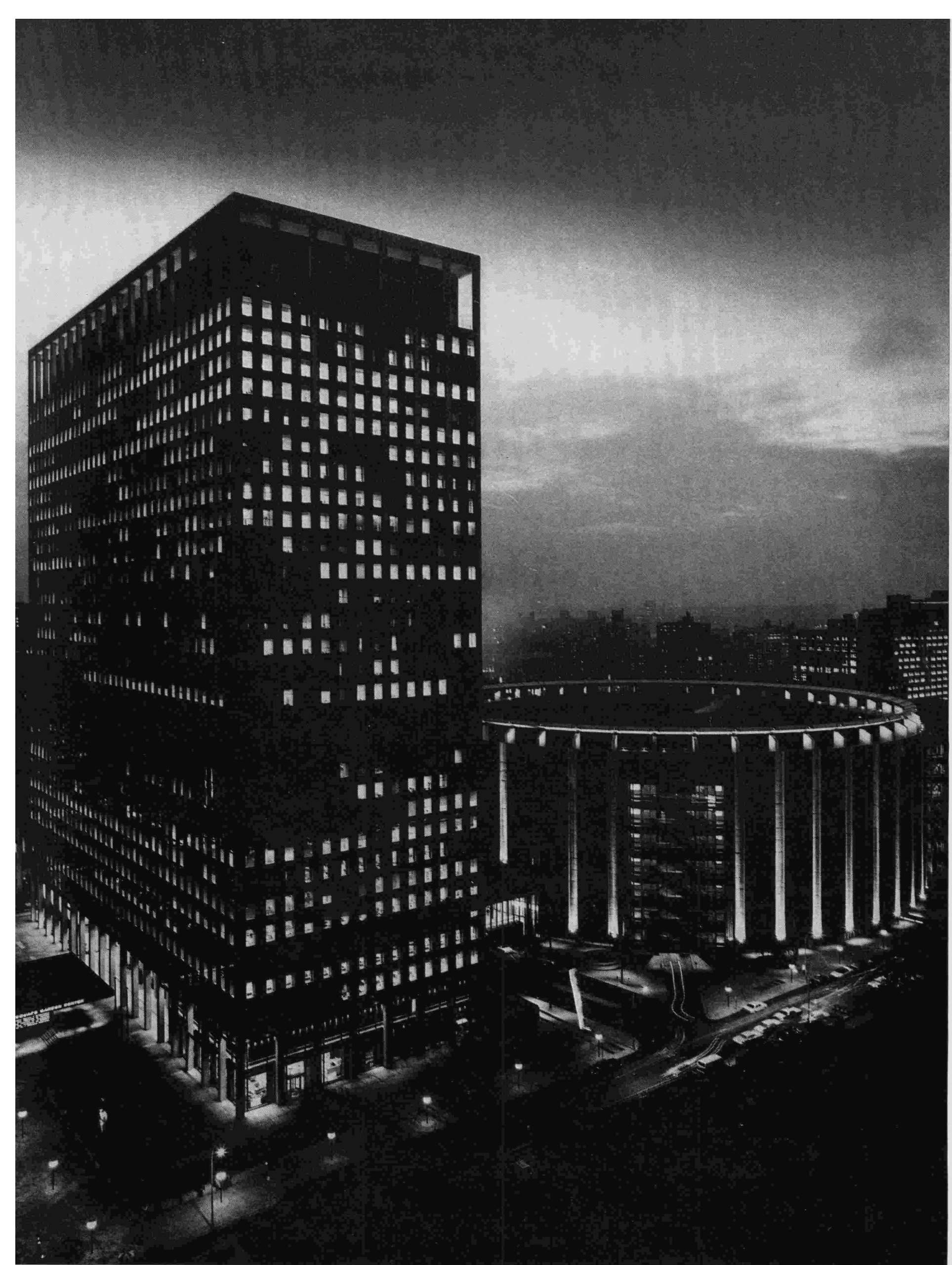




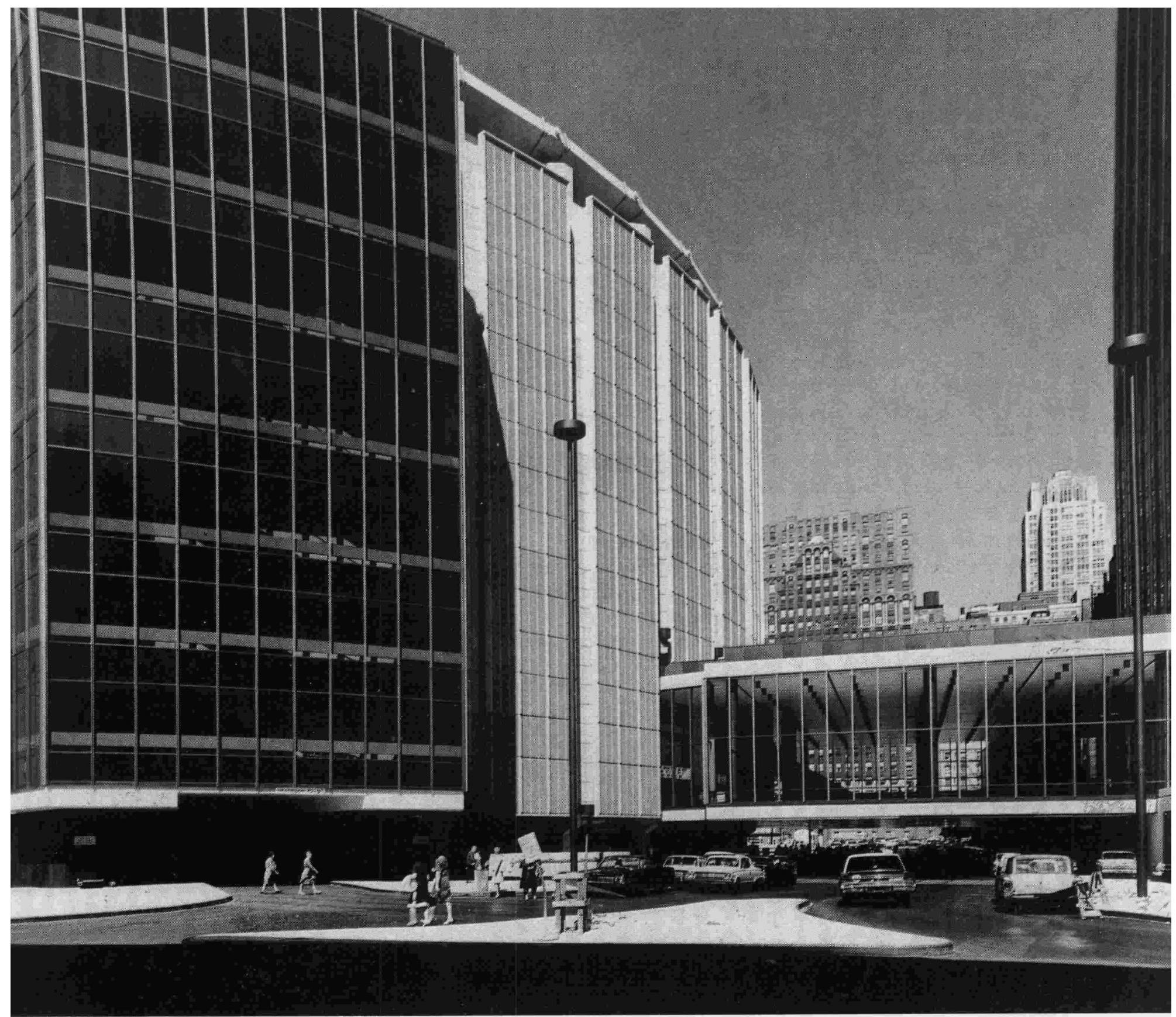

Sobre un solar de $34.400 \mathrm{~m}^{2}$, emplazado en la Pennsylvania Station de Nueva York, rodeado por la Séptima y Octava Avenidas y las calles 31 y 33 , han sido erigidas las nuevas edificaciones del Centro Deportivo y de Atracciones Madison Square Garden.

Aquí nos referiremos, concretamente, al Centro de Reuniones, Exhibiciones, Atracciones y Deportes Madison Square Garden -lindante con la
Octava Avenida-y al edificio de 29 plantas conocido como "Two Pennsylvania Plaza" -en la Séptima Avenida-; rodeados por plazas abiertas y zonas ajardinadas, con esculturas, fuentes, etc.

El Centro Deportivo y de Atracciones Madison Square Garden es un edificio circular, de $129,54 \mathrm{~m}$ de diámetro y $45,72 \mathrm{~m}$ de altura, que aloja el Nuevo Madison Square Garden y otras muchas insta- laciones; tiene una capacidad de 20.250 asientos, y desde todos ellos el espectador puede disfrutar de una visibilidad clara y sin obstáculos, al no existir ninguna columna interior, puesto que la cubierta es colgada.

Además de la pista principal existe otra más pequeña — "forum" - con 4.000 asientos fijos, a los que pueden añadirse 500 más; al lado de 
la planta de la pista aparecen organizados: los espacios destinados a exposiciones; un cine de 500 localidades; salón de actos del Madison Square Garden; un museo de arte deportivo y biblioteca deportiva; y una bolera con 48 pistas, y asientos para espectadores; con instalaciones de televisión, salas de descanso, etc. El foro, el cine y el museo pueden unirse para ser utilizados en un acto determinado, y la pista, a su vez, puede ser convertida en una de las mayores "salas de congresos" del país.

En el Nuevo Garden hay tres clubs: el Madison Square Garden, para socios privados; un nuevo Arena Club, destinado a los abonados que adquieren abonos por localidades para cualquiera de los deportes o acontecimientos presentados en el Garden o en el "forum"; y el de Prensa, para los promotores de deportes u otras actividades dentro del complejo.

Conforme hemos apuntado anteriormente, el Nuevo Garden es fácilmente convertible en el mayor y más moderno salón de asambleas y exhibiciones del mundo y permite, además, que el "forum", el cine y las zonas de exposición puedan ser integradas para la celebración de asambleas, exposiciones industriales, reuniones mercantiles, etc. Tiene una capacidad de $528.000 \mathrm{~m}^{3}$ y un espacio en planta aprovechable de $83.610 \mathrm{~m}^{2}$.

Asimismo, las instalaciones del Garden fueron especialmente diseñadas para que el edificio pudiera servir para la celebración de espectáculos: hockey, baloncesto, ciclismo, boxeo, circo, patinaje sobre hielo, acontecimientos especiales, variedades, asambleas, y otros deportes de masas; pudiendo ser incluso montada una piscina portátil especial, que se coloca rápidamente sobre la cancha, facilitando la celebración de competiciones y exhibiciones de natación, saltos, etc.

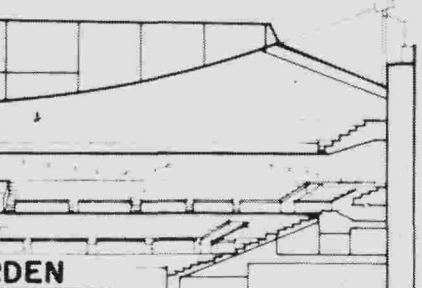
MADISON SQUARE GARDEN $\rightarrow$ BOLERA FORUN CAMIONES CAMIONES

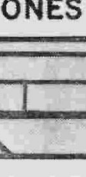




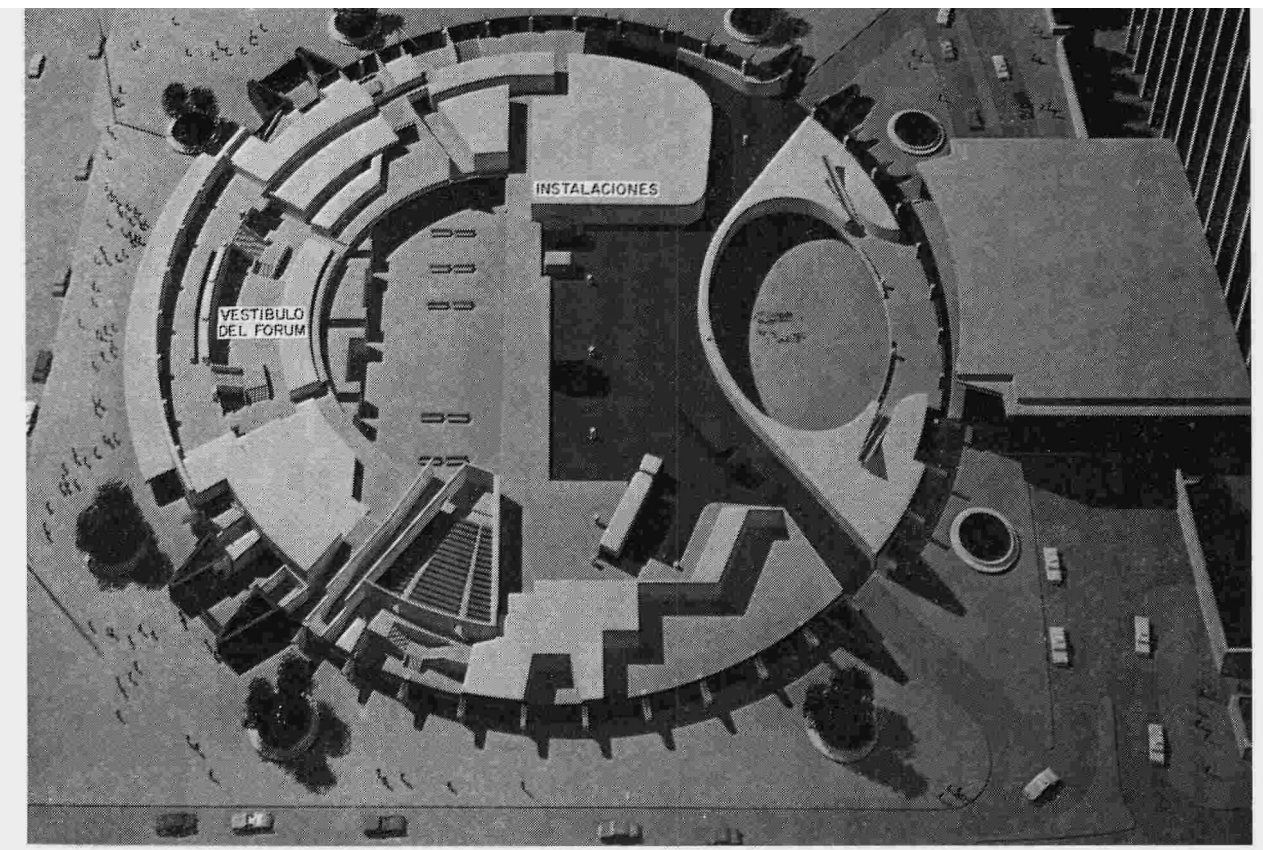

planta

de instalaciones

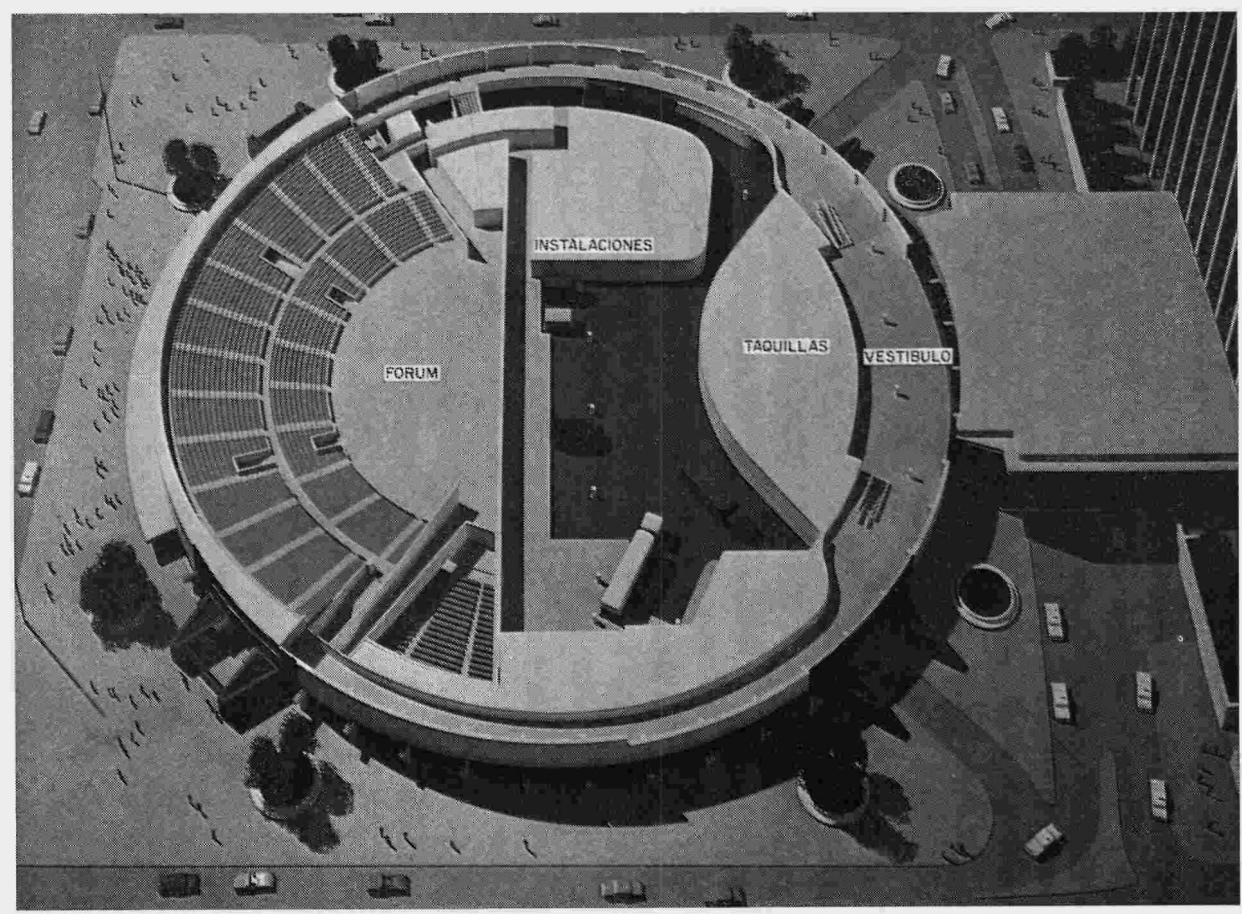

planta de taquillas

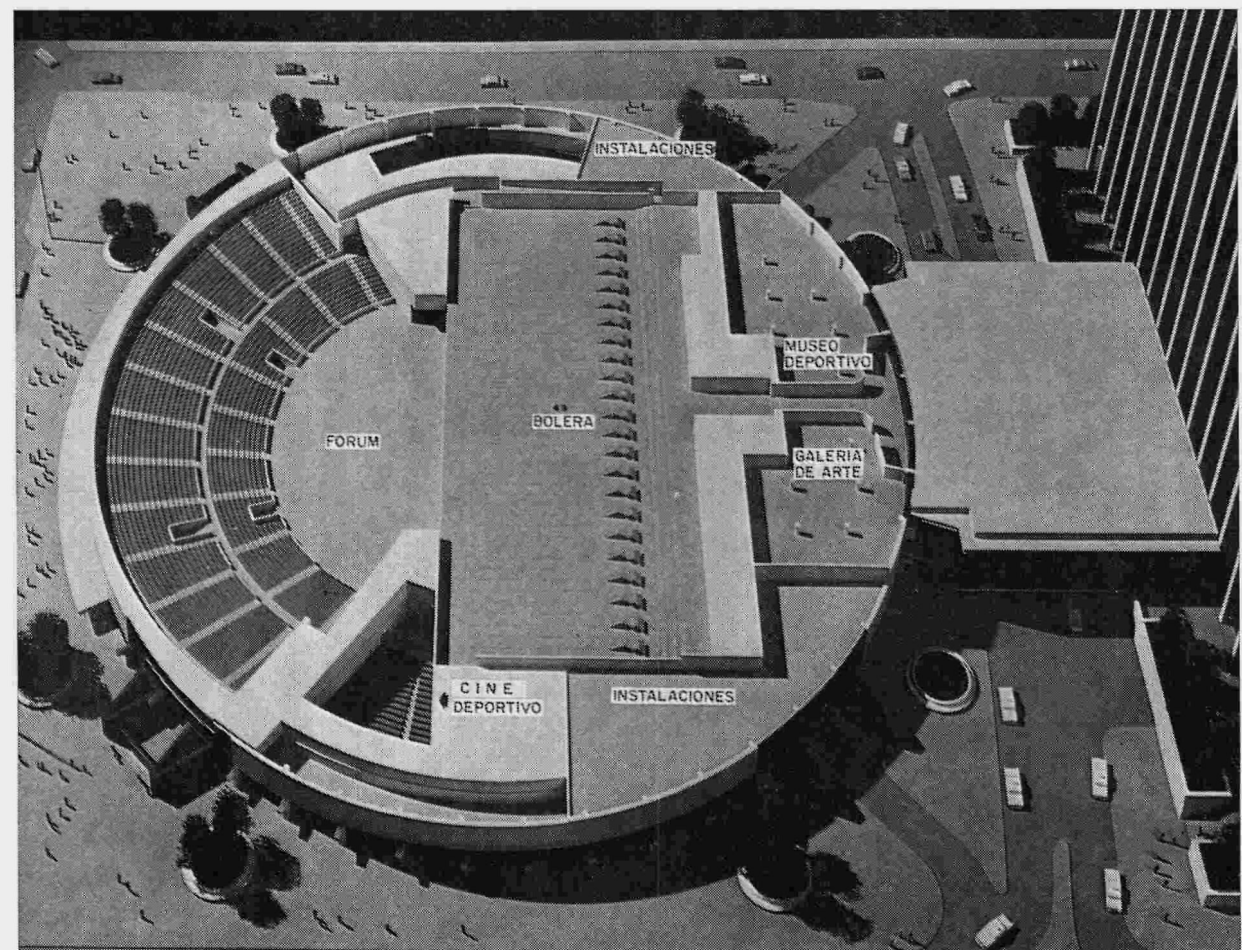

planta de boleras 


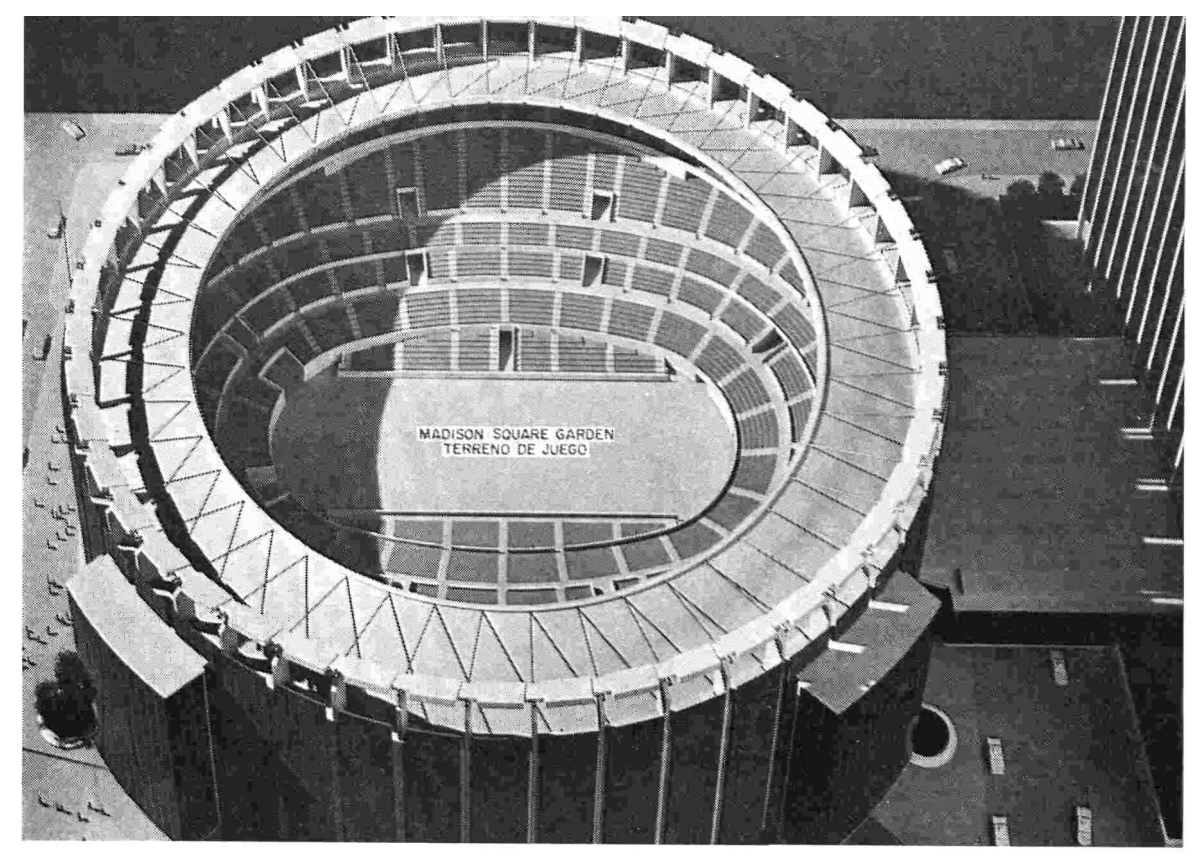

vista aérea

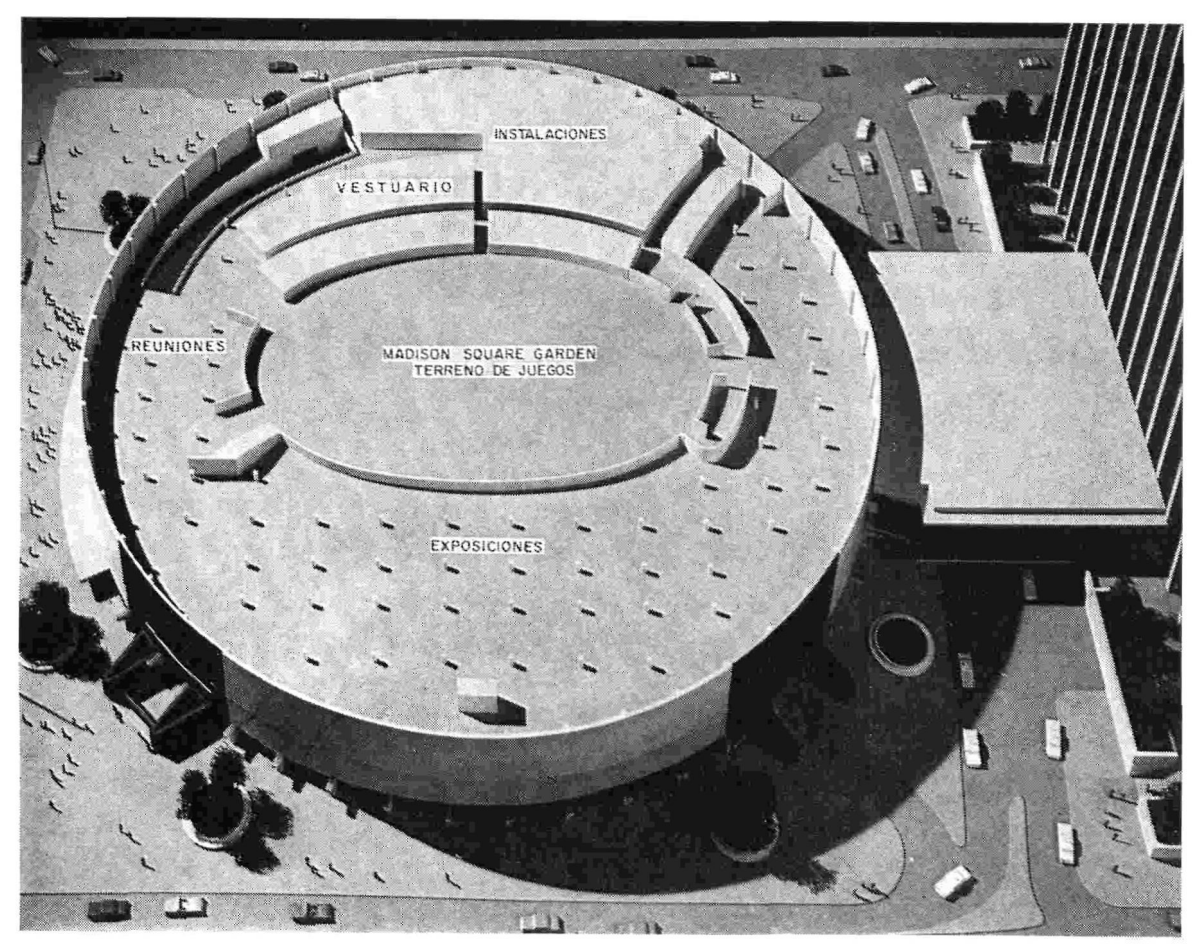

planta de exposiciones

La estructura del Nuevo Madison Square Garden consta de unos pescantes radiales en voladizo, realizados a base de hormigón armado, que van hacia arriba y hacia afuera y que sirven de apoyo a los elementos de los asientos. Estos pescantes terminan, en su parte superior, en un anillo elíptico de hormigón que trabaja a compresión. Los asientos son del tipo estadio.

La entrada a las gradas se realiza a una altura intermedia, a fin de que los espectadores, subiendo o bajando desde estos emplazamientos hasta su localidad, recorran aproximadamente idéntico trayecto.

El anillo de compresión —anteriormente mencionado- empleado para estabilizar la red de cables suspendidos presenta un eje mayor de 164,6 m, en dirección E.-O., y un eje menor de 122 m, en dirección N.-S.; los extremos oriental y occidental del anillo se elevan más que los extremos sep- 

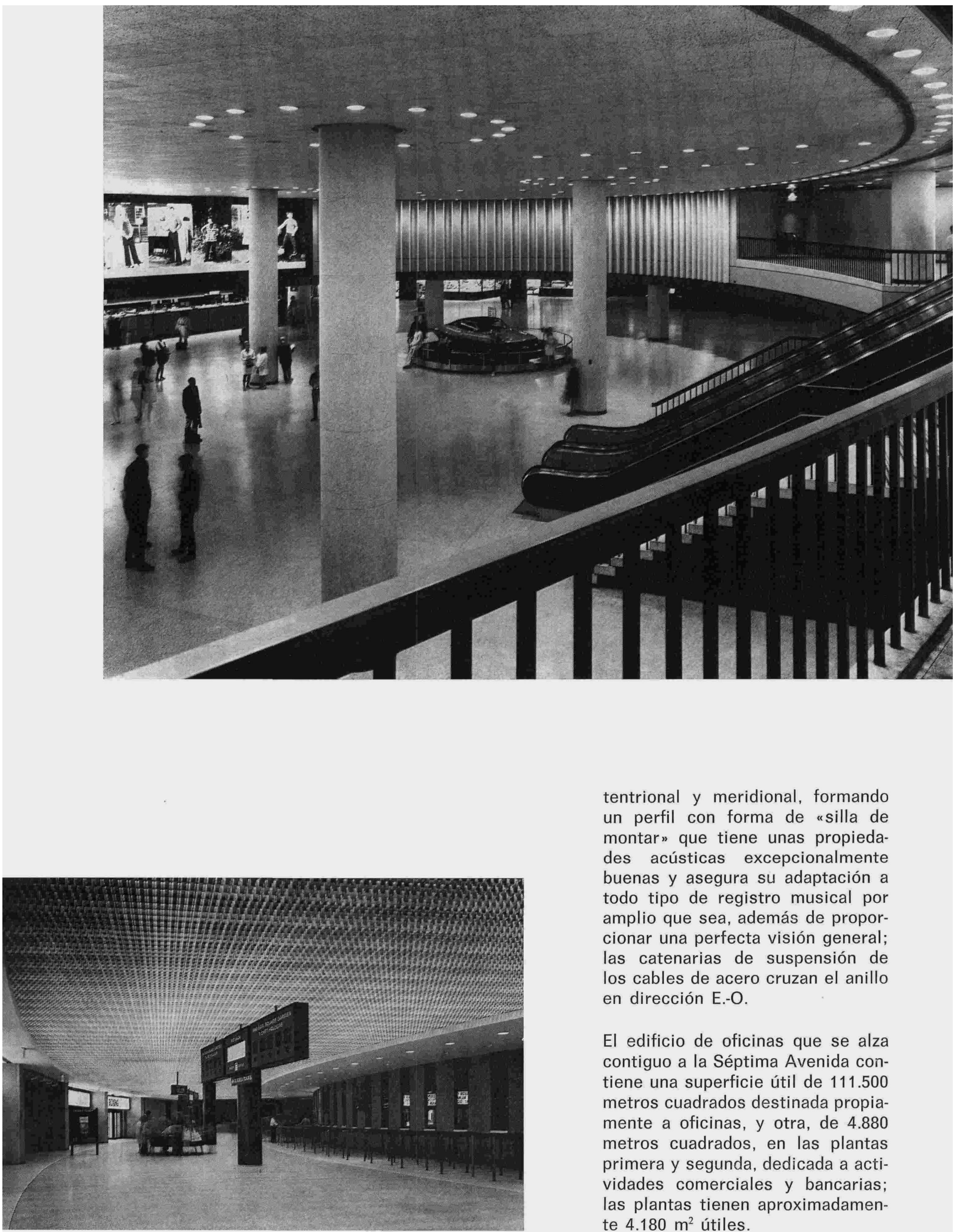

tentrional y meridional, formando un perfil con forma de "silla de montar" que tiene unas propiedades acústicas excepcionalmente buenas y asegura su adaptación a todo tipo de registro musical por amplio que sea, además de proporcionar una perfecta visión general; las catenarias de suspensión de los cables de acero cruzan el anillo en dirección E.-O.

El edificio de oficinas que se alza contiguo a la Séptima Avenida contiene una superficie útil de 111.500 metros cuadrados destinada propiamente a oficinas, y otra, de 4.880 metros cuadrados, en las plantas primera y segunda, dedicada a actividades comerciales y bancarias; las plantas tienen aproximadamente $4.180 \mathrm{~m}^{2}$ útiles. 


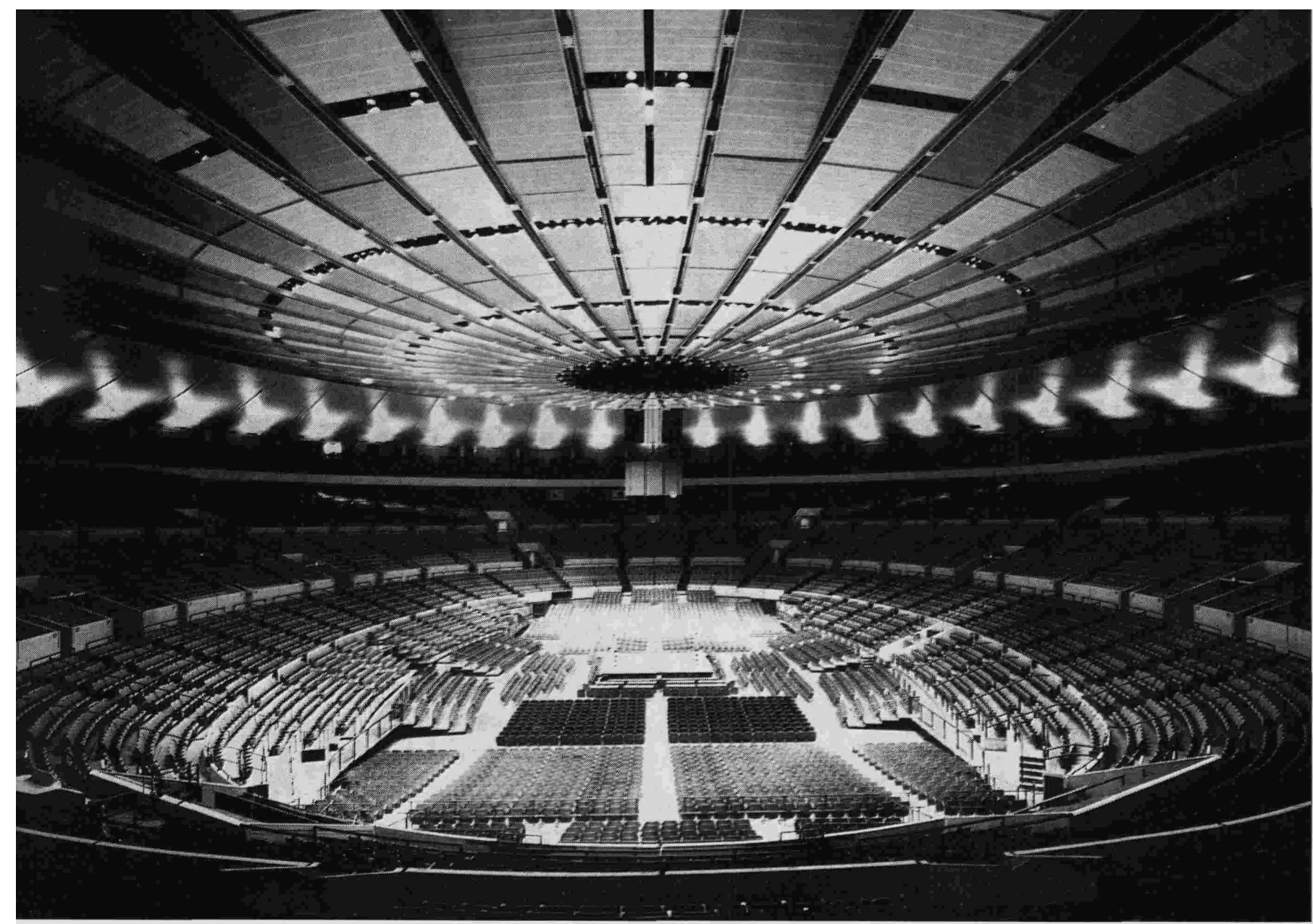

El Centro deportivo y el edificio de oficinas aparecen separados por un pasaje particular — con 4 vías de circulación-, que va desde la calle 31 hasta la 33, empleado fundamentalmente por los taxis y los coches particulares de los visitantes de ambos edificios.

Un paso elevado para peatones - cerrado con vidrieras-, de $51 \mathrm{~m}$ de longitud y $40 \mathrm{~m}$ de ancho, conduce desde el edificio de oficinas hasta el centro deportivo y hasta el vestíbulo, en el que se distribuyen las taquillas.

Los espectadores entran al propio Garden utilizando una de las cuatro escaleras automáticas situadas en su periferia.

Se ha efectuado un cuidadoso estudio y una perfecta y maravillosa iluminación del conjunto, tanto en su exterior como en los alrededores e interiores.

\section{résumé}

Le nouveau Madison Square

\section{Garden - Etats-Unis}

Charles Luckman, architectes associés

Le Centre Sportif et d'Attractions Madison Square Garden comprend:

- Un édifice circulaire, de $129,54 \mathrm{~m}$ de diamètre et $45,72 \mathrm{~m}$ de hauteur, qui abrite le nouveau Madison Square Garden et beaucoup d'autres installations. Contenant 20.250 sièges, il peut être destiné tenant 20.250 sieges, il peut etre destine a des spectacles de hockey, basket-ball, gla glace, assemblées, sports de masses,

- un édifice pour bureaux qui s'élève contigu de la 7th Avenue, avec une superficie de $111.500 \mathrm{~m}^{2}$ destiné aux bureaux proprement dits et une autre superficie de $4.800 \mathrm{~m}^{2}$, aux premier et deuxième étages, réservée à des activi tés commerciales et bancaires.

\section{summary}

The New Madison Square Garden, U. S.

Charles Luckman Associates, architects

The Madison Square Garden Sports and Amusements Center comprises the following.

1. A circular building, $129.54 \mathrm{~m}$ in diameter and $45.72 \mathrm{~m}$ high, which houses the New Madison Square Garden and many other facilities. The arena sits 20.250 spectators, who can watch hockey, basketball, cycling, boxing, circus shows, ice skating, special displays, variety shows, meetings and other kinds of performance.

2. An office block on Seventh Avenue, with a useful floor area for office use amounting to $111,500 \mathrm{~m}^{2}$ and a further $4,800 \mathrm{~m}^{2}$ of floor area on the first two floors for commercial and banking activities.

\section{zusammenfassung}

Der neue Madison Square Garden - USA

Charles Luckman Associates, Architekten

$\mathrm{Zu}$ dem Sportzentrum und Vergnügungspark Madison Square Garden gehören:

1) ein Rundbau mit einem Durchmesser von $129,54 \mathrm{~m}$ und einer Höhe von $45,72 \mathrm{~m}$, in dem der neue Madison Square Garden und andere Einrichtungen untergebracht sind. Er verfügt über 20.250 Platze und er ist geeignet für folgende Veranstaltungen: Hockey, Korbball, Radsport, Boxen, 2irkus, Schlittschuhlaufen, besondere Veranstaltungen, sportarten, usw.

2) ein Bürogebäude, das an der 7th Avenue gelegen ist. Es hat eine Nutzflache von $111.500 \mathrm{~m}^{2}$ für Büroräume und weitere $4.800 \mathrm{~m}^{2}$ im ersten und zweiten Geschoss für Geschäfts- und Bankräume. 